\title{
Epidemiological Study on Ticks infestations in Cattle of Jharkhand and Therapeutic Evaluation of Cypermethrin, Deltamethrin and Flumethrin
}

\author{
Sudhanshu Shekhar*1 and J.P. Singh ${ }^{2}$ \\ ${ }^{1}$ Krishi Vigyan Kendra (ICAR-NRRI), Jainagar, Koderma, Jharkhand, INDIA \\ ${ }^{2}$ Department of Veterinary Medicine, C.V.A.Sc. E A. H, ANDUAT, Kumarganj, Ayodhya, Uttar Pradesh, INDIA
}

"Corresponding author: S Shekhar; E-mail: sudhanshukoderma@gmail.com

Received: 09 July, 2020

Revised: 20 Oct., 2020

Accepted: 08 Nov., 2020

\begin{abstract}
The present study was conducted to find out prevalence of ticks infestation in cattle and comparative therapeutic efficacy of cypermethrin, deltamethrin and flumethrin in dairy cattle of district Koderma, Jharkhand, India. Total 3890 cattle were examined out of them 1602 cattle were found infested with different species of ticks. The overall prevalence of ticks in cattle were recorded $41.18 \%$. Among them 876 (54.68 \%) cattle were infested by Boophilus microplus followed by Hyalomma anatolicum anatolicum, 332 (20.72\%), Haemaphysalis bispinosa $261(16.29 \%)$ and $133(8.30 \%)$ with multiple species of ticks. Round the year prevalence of tick were recorded in the cattle and highest (65.84\%) prevalence were recorded during month of September and lowest (24.22\%) prevalence were in March. Prevalence was noticed higher in monsoon/ rainy season (60.53\%) followed by winter season (34.21\%) and summer season (28.25\%). Prevalence of ticks infestations were significantly higher in young cattle (up to one year), cross breed, female, reared under intensive system. The common sites of predilection of ticks were udder, perineum, groin, and dewlap and flank region. After 28 days post treatment by cypermethrin, deltamethrin and flumethrin, reduction in mean ticks population density were $74.94 \%, 78.84 \%$ and $100 \%$, respectively.
\end{abstract}

\section{HIGHLIGHTS}

(0 Season, species, age, sex, breed, system of rearing and sites of predilection wise variations in prevalence of ticks in cattle.

(- Comparative therapeutic efficacy of cypermethrin, deltamethrin and flumethrin in ticks infested cow.

Keywords: Boophilus microplus, Cattle, Cypermethrin, Deltamethrin, Flumethrin, Prevalence, Ticks

In the last few decade prevalence of vector-borne diseases are increases in livestock. The increases in prevalence of vector borne diseases might be due to effect of climate change, resistance occurred due to indiscriminate use of insecticides, poor animal husbandry practices and mal nutrition etc. Five majors arthropods species viz., flies (non-biting and biting), fleas, lice (sucking and biting), ticks (hard and soft), and mites (follicular, nonburrowing and burrowing) infested livestock. Among these arthropods species, ticks and flies are the important vectors that transmit many protozoans, rickettsial, bacterial and viral diseases in cattle. Among the total world's cattle populations about $80 \%$ are infest with different species of ticks (FAO, 2004) and causes considerable financial losses to livestock industries in the form of mortality, loss of production, decreased work efficiency and increased cost for prevention and control (Uilenberg, 1995; Makala et al., 2003). In India, ticks are widely distributed in all agro-climatic zones and 106 species of Ixodid ticks has been reported from different parts of the country (Ghosh et al., 2007). Among them Rhipicephalus (Boophilus) sp., Hyalomma sp., Haemaphysalis sp. and Amblyomma sp. are very common ticks of cattle in tropical countries.

How to cite this article: Shekhar, S. and Singh, J.P. (2020). Epidemiological study on ticks infestations in cattle of Jharkhand and therapeutic evaluation of cypermethrin, deltamethrin and flumethrin. J. Anim. Res. 10(6): 967-972.

Source of Support: None; Conflict of Interest: None क) 
The losses cause due to ticks infestation and tick borne diseases in the country were estimated more than ₹ 2000 crores annual (Ghosh et al., 2007). The incidences of ticks infestations in cattle depends on various factors like temperature, humidity, rainfall of that place and age, sex, breed and system of rearing of the cattle. The systematic prevalence of Ixodid ticks infestations in cattle of the area is still lacking, which hampers the planning of an effective arthropod control. The common method for control of ticks in cattle is application of acaricides however; indiscriminate and repeated use lead to development of resistance in ticks (Martins et al., 1995). There are different classes of acaricides, likes Organophosphates, Carbamates, Pyrethroids, Amitraz and Avermectin were used for control of tick' populations in cattle (Schroder et al., 1985; Bagharwal and Ashok 1992; Mekonne, 2001; Petro et al., 2012). Among them synthetic pyrethriods are environmentally safe and relatively less toxic to livestock and other non-target organisms, prolonged (7-10 days) residual activity and comparatively inexpensive. Keeping view of above facts present study was designed to find out prevalence of ticks in cattle and comparative therapeutic efficacy of cypermethrin, deltamethrin and flumethrin against tick infestation in dairy cows of Koderma district of Jharkhand, India.

\section{MATERIALS AND METHODS}

The present investigation was undertaken in Koderma district of Jharkhand, India during the period from March 2019 to February 2020 the ticks were collected from 3890 cattle covering 150 small scale unorganized randomly selected dairy farms.

\section{Prevalence study}

A cross sectional analysis was conducted to find out the prevalence in month, seasons, age, sex and breed and system of rearing wise of ticks and site of attachment on the body surface of the cattle. The prevalence study was conducted in three season's viz. summer season (March to June), monsoon/ rainy season (July to October) and winter seasons (November to February). Age wise prevalence was recorded by dividing the selected cattle on the basis of their age group. Group I contains younger cattle up to 1 year of age and group II contains growing cattle between 1 to 3 years while group III contains adult cattle more than
3 years. Sex, breed and system of rearing wise prevalence of ticks were recorded in cattle by dividing them into respective groups. The selected cattle farms were visited as per need to collect the relevant data. The prevalence was recorded as per methods described by (Thrusfield, 1995).

\section{Collection, identification and preservation of Ixodid ticks}

The ticks (engorged and unengorged) were plucked from the body of the host by hand pick or with the help of blunt forceps without damaging their mouth parts. Each cattle examined for ticks infestations was considered as one sample. The samples were collected separately in well ventilated, proper labelled (date, age, sex, breed, management practice and site of attachments) plastic containers and preserved in to $70 \%$ alcohol. These ticks were identified by methods described by (Soulsby, 2006).

\section{Therapeutic trial}

An On Farm Trial (OFT) was conducted in 40 ticks infested cattle by randomly dividing in to four groups' viz. T1, T2, T3 and TC. The cows of T1 were applied Cypermethrin (Clinar ${ }^{\circledR}-10 \%$ w/v, Virbac, Animal health, Pvt. Ltd.) (a) $1 \mathrm{ml} /$ litre of water), T2 were applied Deltamethrin (Butox ${ }^{\circledR}$-12.5 mg / ml MSD pharmaceutical, Pvt. Ltd,) @ $3 \mathrm{ml} /$ litre of water), and T3 were applied Flumerthtrin-1\%, (Flumitas ${ }^{\circledR}-10 \mathrm{mg} / \mathrm{ml}$, pour on, Intas pharmaceutical, Pvt. Ltd). The drug used in different treatment groups was applied once in a week for three consecutive weeks. The cows of group TC kept as infected control and no any drug was applied. The efficacy of drugs were determined by reduction in ticks count in $10 \mathrm{~cm}^{2}$ areas of three different regions on the body surface of the cow on $0,7,14,21$ and 28 days of post treatment (Ongare et al., 1983). No any insecticides / chemicals or any other control measures of ticks were used in premises.

\section{Statistical analysis}

The data were analyzed by statistical software program SPSS. A one-way Analysis of variance (ANOVA) was used for comparison of means.

\section{RESULTS AND DISCUSSION}

Out of 3890 cattle examined, 1602 cattle were infested 
with different species of ticks. The overall prevalence was 41.18 percent (Fig. 1).

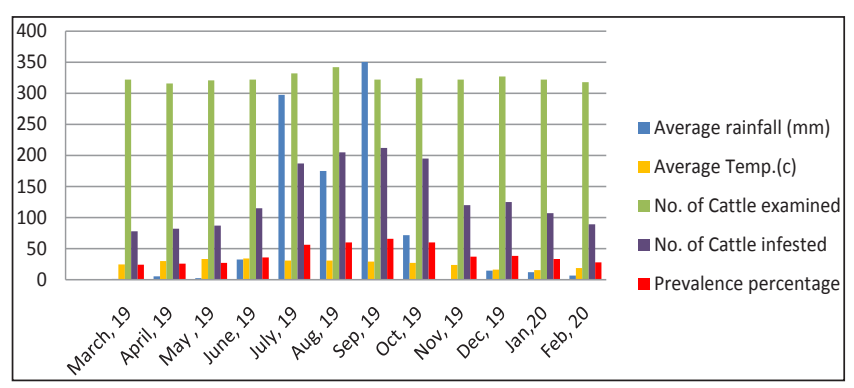

Fig. 1: Average rainfall, temperature and month wise prevalence (\%) of ticks in cattle

In contrast to present finding higher prevalence of ticks were recorded by earlier workers in cattle (Patel et al., 2013; Singh and Rath, 2013; Kaur et al., 2017) however, others works have reported low prevalence of ticks infestation (Manan et al., 2008; Vatsya et al., 2008). Overall prevalence of ticks in cattle were varied in different parts of country might be due to difference in managemental practices, breeds, macro and micro climatic condition and geographical location of the region. Most of the cattle infested with Boophilus microplus 876 (54.68\%), followed by Hyalomma anatolicum anatolicum, 332 (220.72 \%), Haemaphysalis bispinosa, 261 (16.29\%) and multiple species of ticks 133 (8.30\%) (Fig. 2).

\begin{tabular}{|c|c|}
\hline Boophilus microplus & Hyalomma anatolicum anatolicum \\
\hline Haemaphysalis bispinosa & Mixed species of ticks \\
\hline
\end{tabular}

Fig. 2: Prevalence percentage of different species of ticks in cattle

Single and multiple species of ticks' infestation were recorded and Boophilus microplus was the most prevalent species of ticks in cattle. The higher prevalence of Boophilus microplus might be due climatic conditions and thick hair coat of cattle (Khan, 1994). In present investigation round the year tick infestations were recorded in cattle and highest $(65.84 \%)$ prevalence was recorded in the month of September and lowest $(24.22 \%)$ prevalence was recorded in the month of March. Similar findings recorded by (Khan and Srivastava, 1994; Patel et al., 2013). Prevalence of ticks infestations in study population was recorded higher in monsoon/ rainy season followed by winter season and summer season and prevalence percentage were recorded $60.53 \%, 34.21 \%$ and $28.25 \%$, respectively. The season wise variations in prevalence of ticks were observed by earlier workers from different regions of the country and world (Vatsya et al., 2008; Rony et al., 2010; Atif et al., 2012). The high incidence in monsoon seasons might be due to hot and humidity climatic conditions, which favours growth and development of tick population. Ticks infestations were recorded high in young cattle of below one year and low in cattle of more than 3 years old (Fig. $3)$.

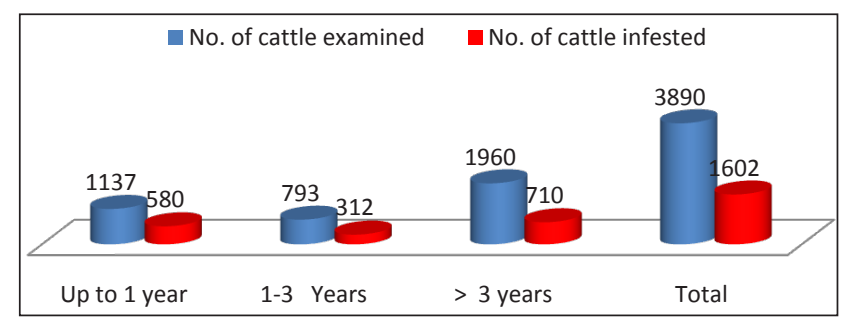

Fig. 3: Age wise prevalence of ticks in cattle

The findings were correlated with facts that young or unproductive animals are given little care and attention, low plan of nutrition and close confinement leads to higher prevalence of ticks. Comparatively low prevalence of ticks in adult cattle might be development of acquired immunity due to repeated exposure of ticks' infestations in earlier age. Similar pattern of infestations of ticks in cattle was observed by (Singh, 1997; Manan et al., 2008). The significantly higher prevalence of ticks was recorded in female cattle as compared to male cattle (Fig. 4).

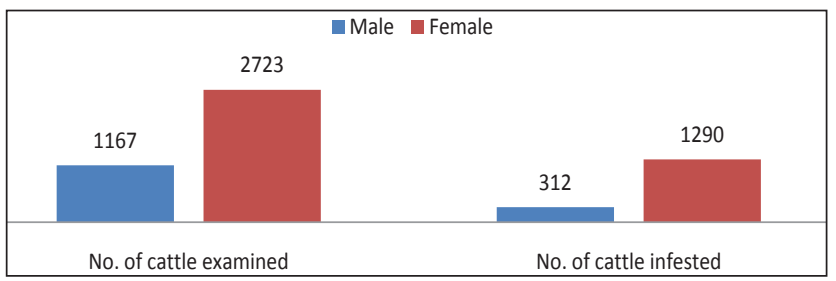

Fig. 4: Sex wise prevalence of ticks in cattle

The high prevalence of ticks' infestation in female cattle may be due to various stress factors likes hormonal, 
pregnancy and lactation stress, which makes them susceptible to many infection (Sutherst et al., 1983). The higher prevalence of ticks infestations were recorded in cattle reared under intensive system as compared to reared under semi-intensive system. (Fig. 5).

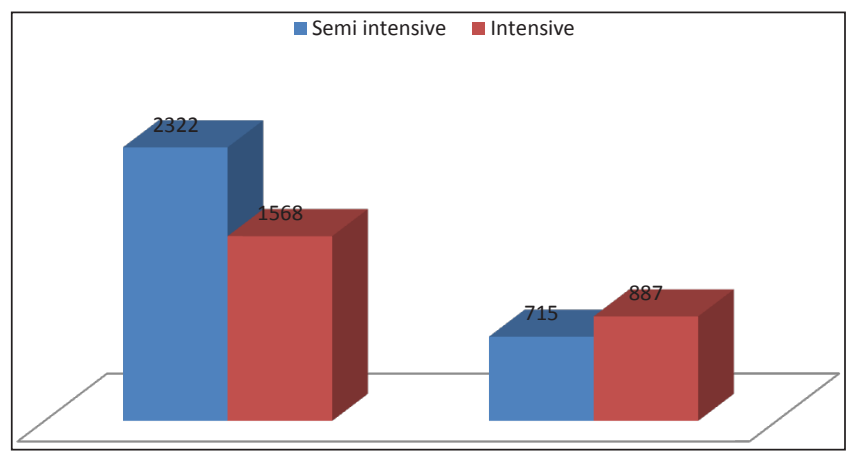

Fig. 5: System of rearing wise prevalence of ticks in cattle

The higher prevalence of ticks in cattle reared under intensive system might be due to closed confinement which provides greater chance of contact between cattle, leads to more infestation of ticks. In contrast to present findings higher prevalence of ticks were recorded in cattle reared under extensive system (Kabir et al., 2011; Tiki and Addis, 2011). The significantly higher prevalence of ticks was recorded in cross breed (HF) cattle as compared to deshi (Zebu) cattle. Similar findings reported by (Atif et al., 2012; Asmaa et al., 2014).

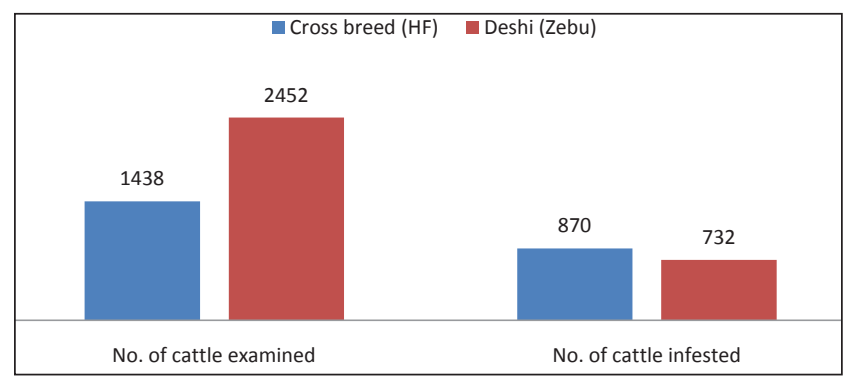

Fig. 6: Breed wise prevalence of ticks in cattle

Prevalence of ticks infestations were low in indigenous cattle (Zebu) might be due to strong natural immunity, thick hides, short and straight hair and secretion from sebaceous gland that repellent the ticks. Site of attachment/ predilection of ticks on the body surface of cattle revealed that udder, perineum, groin, dewlap and flank region were high ticks infested areas. (Fig. 7). Site of attachments of ticks on host body depends on various factors viz. species of ticks, population density, time, season, and frequency of grooming etc. (Chandler and Read, 1994; Kettle, 1995; Seyoum, 2005).

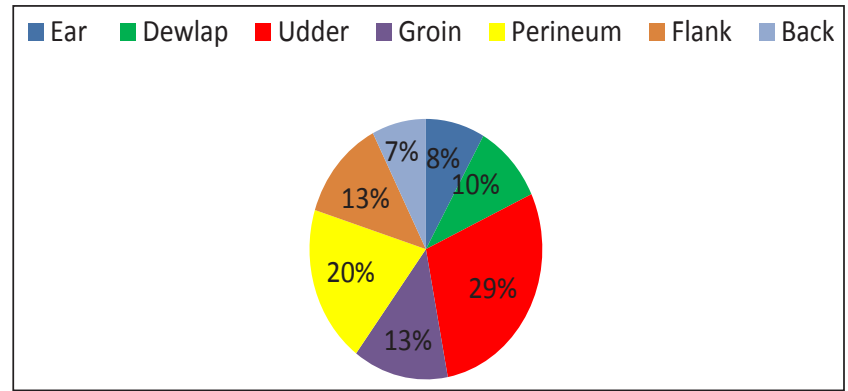

Fig. 7: Site of attachments of ticks in cattle

The site of attachment of ticks helps in monitoring and control of ticks' infestations in cattle. In therapeutics study revealed that on day 7 of post treatment significant $(\mathrm{P}<0.05)$ reduction in mean tick population density was noticed in cows of cypermenthrin, deltamethrin and flumethrin treated groups and reduction percentage were recorded $21.25 \%, 32.07 \%$ and $73.0 \%$ respectively. In infected control group $(\mathrm{TC})$ significant $(\mathrm{P}<0.05)$ increased in population density of ticks were recorded on different days of trial period (Table 1). In all treatment groups' significant $(\mathrm{P}<0.05)$ reduction in mean ticks count were recorded on different days of acricidal applications. On 28 day of post treatment in cypermethrin, deltamethrin and flumethrin treated groups recorded $74.94 \%, 78.84 \%$ and $100 \%$ reduction in mean tick population density in cattle. The low efficacy of cypermethrin and deltamethrin might be due to widely used of these synthetic pyrethroides exerts selection pressure on the ticks' leads to development of resistance in the tick populations. Earlier works also recorded variation in potency of cypermethrin and deltamethrin against susceptibility of ticks (Ghosh et al., 2006; Sharma et al., 2012; Shyma et al., 2013; Jyotimol et al., 2014). Flumethrin, as pour-on apply weekly for three weeks found to be very effective for control of ticks' infestations in cows. Flumethrin, as a pour-on, has a remarkable capacity of rapid spreading from site of application i.e., dorsal line of an animal body to skin, hair and all other parts of the body surface. Pour-on formulation of flumethrin extended the residual effect of treatment. The cis-cypermethrin isomer and deltamethrin are 50 times less toxic to Boophilus microplus as compared to trans- 
Table 1: Ticks count (Mean \pm SE) in different days of treatment in Cypermethrin, Deltamethrin and Flumethrin treated group of cattle

\begin{tabular}{llllll}
\hline Group & Day 0 & Day 7 & Day 14 & Day 21 & Day 28 \\
\hline T1 & $21.35 \pm 1.48^{\mathrm{a}}$ & $16.75 \pm 2.25^{\mathrm{b}}(21.25 \%)$ & $12.75 \pm 0.75^{\mathrm{b}}(40.28 \%)$ & $9.25 \pm 0.48^{\mathrm{c}}(56.94 \%)$ & $5.35 \pm 0.38^{\mathrm{d}}(74.94 \%)$ \\
T2 & $22.45 \pm 1.25^{\mathrm{a}}$ & $15.25 \pm 1.17^{\mathrm{b}}(32.07 \%)$ & $10.12 \pm 0.35^{\mathrm{bc}}(54.92 \%)$ & $6.12 \pm 1.32^{\mathrm{c}}(72.73 \%)$ & $4.75 \pm 0.7^{\mathrm{d}}(78.84 \%)$ \\
T3 & $23.15 \pm 1.25^{\mathrm{a}}$ & $6.15 \pm 1.55^{\mathrm{c}}(73.43 \%)$ & $1.25 \pm 1.23^{\mathrm{e}}(94.60 \%)$ & $00 \pm 0.00(100 \%)$ & $00 \pm 0.00(100 \%)$ \\
TC & $22.85 \pm 2.56^{\mathrm{a}}$ & $25.46 \pm 1.75^{\mathrm{b}}$ & $27.15 \pm 1.45^{\mathrm{b}}$ & $29.45 \pm 1.05^{\mathrm{c}}$ & $31.15 \pm 1.65^{\mathrm{c}}$ \\
\hline
\end{tabular}

Superscript differ significantly $(\mathrm{P}<0.05)$ between the rows; Figure in parenthesis indicate percentage; $\mathrm{T} 1$ : Cypermethrin treated; T2: Deltamethrin treated; T3: Flumethrin treated; TC: Infected Control.

flumethrin isomer (Schnitzerling et al., 1989) Flumethrin at low concentration effectively control the different species of ticks' infestation in cattle as compared to other synthetic pyrethroids (cypermethrin and deltamethrin) (Stendel, 1985).

\section{CONCLUSION}

It may be concluded that $41.18 \%$ of cattle were infested with different species of ticks and most prevalent species of ticks were Boophilus microplus. Ticks infestations were recorded round the year and highest prevalence were in month of September and lowest prevalence were recorded in the month of March. Prevalence of ticks were higher in monsoon/ rainy season followed by winter season then summer season. Prevalence were significantly higher in young cattle (below one year), cross breed, female cattle reared under intensive system. The common sites of predilection of ticks in cattle were udder, perineum, groin, and dewlap and flank region. Flumethrin-1\%, as pour-on applies once in a week for three weeks found very effective to control the ticks' infestations in cows.

\section{ACKNOWLEDGEMENTS}

The authors are thankful to Director, ICAR-ATARI, Patna, Bihar and Director, ICAR, NRRI-Cuttack, Odisha for providing fund and the necessary facilities to carry out the investigation.

\section{REFERENCES}

Asmaa, N.M., El Bably, M.A. and Shokier, K.A. 2014. Studies on prevalence, risk indicators and control options for tick infestation in ruminants. J. Basic Appl. Sci., 3: 68-73.

Atif, F.A., Khan, M.S., Iqbal, H.J., Ali, Z. and Ullah, S. 2012. Prevalence of cattle tick infestation in three districts of the Punjab, Pakistan. Pakistan J. Sci., 64(1): 49-52.
Bagharwal, R.K. and Ashok, S. 1992. Efficacy of Amitraz (12.5\%) against different stages of ticks (Hyalomma anatolicum anatolicum) under experimental and clinical trials. Indian Vet. Med. J., 16: 296-298.

Chandler, C. and Read, P. 1994. Introduction to Parasitology. Jhon Weakly and Sons, Inc. U.K., pp. 882.

FAO, 2004. In: Resistance Management and Integrated Parasite Control in Ruminants: Guidelines Module 1. Rome: Animal Production and Health Division, Food and Agriculture Organization of the United Nations; Ticks: Acaricide resistance, diagnosis, management and prevention, pp. 2577.

Ghosh, S., Azhahianambi, P. and Furente, J.D.L. 2006. Control of ticks of ruminants, with special emphasis on livestock farming systems in India: present and future possibilities for integrated control-a review. Exp. Appl. Acarol., 46: 49-66.

Ghosh, S., Bansal, G.C., Gupta, S.C., Ray, D., Khan, M.Q. and Irshad, H. 2007. Status of tick distribution in Bangladesh, India and Pakistan. Parasitol. Res., 101(2): S207-S216.

Jyothimol, G., Ravindran, R., Juliet, S., Ajith Kumar, K.G., Suresh, N.N. and Vimal Kumar, M.B. 2014. Low level Deltamethrin resistance in ticks from cattle of Kerala, a south Indian state. Vet. Parasitol., 204: 433-438.

Kabir, M.H.B, Mondal, M.M.H., Eliyas, M., Manan, M.A., Hashem, M.A. and Debnath, N.C. 2011. An epidemiological survey on investigation of tick infestation in cattle at Chittagong district, Bangladesh. Afr. J. Microbiol. Res., 5(4): 346-352.

Kaur, D., Jaiswal, K. and Mishra, S. 2017. Epidemiological study of ixodid ticks infesting cattle reared by small holder farmers. J. Entomol. Zool. Stud., 5(4): 284 - 291.

Kettle, D.S. 1995. Medical and Veterinary Entomology. $2^{\text {nd }}$ Ed., C.A.B. International, U.K. pp. 420-460.

Khan, M.H. 1994. Infestation of ticks on cattle and buffaloes in Bareilly, Uttar Pradesh. J. Vet. Parasitol., 8(1) : 71-76.

Khan, M.H. and Srivastava, S.C. 1994. Studies on the hostrange and incidence of Hyalomma (H.) dromedarii. J. Vet. Parasitol., 8(1): 21-25. 
Makala L.H., Mangani, P., Fujisaki, K. and Nagasawa, H. 2003. The current status of major tick borne diseases in Zambia. Vet. Res., 34: 27-45.

Manan, A., Khan, Z., Ahmad and Abdullah, B. 2008. Prevalence and identification of Ixodid tick genera in frontier region Peshawar. J. Agr. Biol. Sci., 2(1): 21-25.

Martins, J.R., Correa, B.L., Cereser, V.H. and Arteche, C.C.P. 1995. A situation report on resistance to acaricides by the cattle tick Boophilus microplus in the state of Rio Grande do Sul, Southern Brazil. In: Rodriguez, C.S. and Fragoso, S.H. (eds) Resistencia Control en Garrapatasy Moscas de Importancia Veterinaria III. Seminario Internacional de Parasitologia Animal, Acapulco, Mexico, pp. 1-8.

Mekonne, S. 2001. In vivo evaluation of amitraz against ticks under field conditions in Ethiopia. J. S. Afr. Vet. Assoc., 72(1): 44-45.

Ongare, J.O., Rinkanya, F.G., Mwangi, E.N. and Kiundi, J.I. 1983. Evaluation of certain ixodicides for the control of Rhipicephalus appendiculatus using a tick-infested paddock. The Kenya veterinarian, 7: 3-6.

Patel, G., Shanker, D., Jaiswal, A.K., Sudan, V. and Verma, S.K. 2013. Prevalence and seasonal variation in ixodid ticks on cattle of Mathura district, Uttar Pradesh. J. Parasit. Dis., 37(2):173-176.

Petro, Y., Kasege, P., Kilasara, D., Kawiche, E. and Temba, V. 2012. The efficacy of Cypermethrin against cattle ticks in Tanzania. J. Bio. Agri. Hc., 2 (11): 98-104.

Rony, A., Mondal, M.M.H., Begum, N., Islam, M.A and Affroze, S. 2010. Epidemiology of ectoparasitic infestations in cattle at Bhawal forest area, Gazipur. Bangl. J. Vet. Med., 8(1): 2733.

Schnitzerling, H.J., Nolan, J. and Hughes, S. 1989. Toxicology and metabolism of isomers of Flumethrin in larvae of pyrethroid-suceptible and resistant strains of the cattle tick Boophilus microplus (Acari: Ixodidae). Exp. App. Acarol., 6: 47-54.

Schroder, J., Swan, E., Soll, M.D., Hotson, I.K. 1985. Efficacy of Ivermectin against ectoparasites of cattle in South Africa. J. S. Afr. Vet. Assoc., 56(1): 31-35.

Seyoum, Z. 2005. Distribution of host parasite relationship of Ixodids ticks in Eastern Amhara, Ethiopia. Ethiop. Vet. J., 9(1): 9-17.
Sharma, A.K., Kumar, R., Kumar, S., Nagar, G., Singh, N.K., Rawat, S.S., Dhakad, M.L., Rawat, A.K.S., Ray, D.D. and Ghosh, S. 2012. Deltamethrin and Cypermethrin resistance status of Rhipicephalus (Boophilus) microplus collected from six agro-climatic regions of India. Vet. Parasitol., 188: 337345 .

Shyma, K.P., Kumar, S., Sangwan, A.K., Sharma, A.K., Nagar, G. and Ray, D.D. 2013. Acaricide resistance status of Rhipicephalus (Boophilus) microplus and Hyalomma anatolicum collected from Haryana. Indian J. Anim. Sci., 83(6): 591-594.

Singh, A.P. 1997. Seasonal dynamics of ixodid tick infestation and its relationship with the occurrence of clinical cases of blood protozoan diseases in crossbred cattle of Ludhiana district. M.V. Sc. Thesis, Punjab Agricultural University, Ludhiana.

Singh, N.K. and Rath, S.S. 2013. Epidemiology of Ixodid ticks in cattle population of various agro climatic zones of Punjab, India. Asian Pac. J. Trop. Med., pp. 947-951.

Soulsby, E.J.L. 2006. Helminths, Arthropods and Protozoa of domesticated animals. $7^{\text {th }}$ Ed., Bailliere Tindall and Cassel Ltd., London, pp. 444-475.

Stendel, W. 1985. Experimental studies on the tickicidal effect of Bayticol Pour-on. Vet. Med. Report, 2: 99-111.

Sutherst, R.W., Kerr, J.D. and Maywald, G.F. 1983. Effect of season and nutrition on the resistance of cattle to the tick Boophilus microplus. Aust. J. Agric. Res., 34: 329-339.

Thrusfield, M. 1995. Veterinary Epidemiology. 2nd Ed., Black Well Science, Ltd., U.K. pp. 182-198.

Tiki, B. and Addis, M. 2011. Distribution of Ixodid ticks on cattle in and around Holeta town, Ethiopia. Glob. Vet., 7(6): 527-531.

Uilenberg, G. 1995. International collaborative research: Significance of tick-borne hemoparasitic diseases to world animal health. Vet. Parasitol., 57: 19-41.

Vatsya, S., Yadav, C.L., Kumar, R.R. and Garg, R. 2008. Prevalence of Ixodid ticks on bovines in the foothills of Uttarakhand state: A preliminary report. Indian J. Anim. Sci., 78(1): 40-42. 